\title{
On clearing agricultural land from undesirable vegetation as a way to improve soil fertility
}

\author{
$S$. Fokin ${ }^{1, *}, D$. Eskov, and P. Medvedeva \\ Saratov State Agrarian University named after N.I. Vavilov, 410012, 1, Teatralnaya sq., Saratov, \\ Russian Federation
}

\begin{abstract}
Russia, with its vast reserves of land, is beginning to experience a shortage of soil suitable for growing crops. At present, many agroindustrial companies are facing a shortage of quality farmland, which hinders business development and production ramp-up. However, the country has a large amount of hidden and unused land reserves. For example, such agricultural land includes thousands of hectares of arable land that have been overgrown with undesirable vegetation as a result of many years of mismanagement. Forest massifs and protective forest belts are necessary to create a favorable environmental situation in the growing area. They are also necessary for agricultural use. So the reforestation plantations protect the soil from water and wind erosion. Indeed, in 1940, the Stalin's plan to create protective forest belts in the steppe zone of the southern Soviet Union, where there was a serious problem of soil erosion, was put into practice. Implementation of this plan continued until 1965, and then the agricultural enterprises maintained the created forest belts in accordance with the regulatory requirements. This required annual removal of young growth, as well as the cutting of brush. But recently, when the necessary activities to maintain the forest belts in their designed condition were practically not carried out, the protective plantations have significantly increased their area. Geometrically, they have become wider by 5,10 , or even 20 meters. Undesirable vegetation, in the form of shrubs and undergrowth encroaches on the field and takes away more area of fertile arable land. In the case of removal of this vegetation field size of 80 100 hectares can be increased by about $5-10 \%$, that is to get up to 10 additional hectares of land suitable for agricultural use. For a farm with a large number of such fields, a significant increase in fertile soil is obtained.
\end{abstract}

\section{Introduction}

In some cases, fields are cleared of unwanted vegetation by hand felling trees and brushwood, and then using tillage equipment to remove the resulting stumps and roots, but this is a long and inefficient procedure, which requires a lot of manual labor. Therefore, a faster and more effective alternative - mechanized stump clearing of the field - can be applied. This requires the stump removal machine to be able to remove all of the above

\footnotetext{
*Corresponding author: feht@mail.ru
} 
ground parts of the stump. At the same time it is necessary that it acts only on the stump, not damaging the surrounding soil cover and not stirring the soil horizons under it.

At the same time it is better to remove the stump from one machine installation, without repeated approaches, in order to avoid soil compaction. Acting on the stump working body should turn the wood into wood chips suitable for use as a mineral fertilizer. Technological methods of stump grinding, remaining in the cleared area, should be carried out with minimal impact of equipment on the soil, by a single passage of machines on one trail. Machine-tractor unit, consisting of a basic general-purpose tractor and a conical cutter with a liquid filler, can be referred to such means for stump removal, but additional research aimed at the formation of design and technological parameters of the new equipment is necessary $[1,2,3]$.

\section{Methods}

Studies have shown that in the steppe and forest-steppe climatic zones of the Volga region stumps with a complex shape of the end cut prevail [4]. Therefore, it is necessary to use fillers, including liquid fillers, to stabilize the working body during chopping at the end part of the stump. Such a working organ is a conical milling machine with liquid fillers [5], which has in its design a centering feather drill and a cross-shaped coupling for connection to a mechanical drive.

The modeling of the conical cutter was based on the methods of classical dynamics. In order to simulate in the model the operation of the cutter, it is necessary to break it down into separate subsystems and develop adequate models of each of them: mechanical and hydraulic subsystems of the cutter linkage and feed; cutter body; liquid filler of the cutter; and the chopped stump. The simulation model is based on a cumbersome system of algebraic and differential equations that describe: the mechanical motion of the feed system and cutter rotation; the behavior of the hydraulic feed system; the behavior of the liquid cutter filler and its interaction with the cutter; the behavior of the stump as a fragmented body, and the interaction of the cutter with the stump.

Taken together, these processes are extremely complex, the equations describing them contain discontinuous functions, so the system of equations is solved not by analytical simplifications, but by direct numerical methods using a modern high-performance computer. In particular, a modified Euler-Cauchy method [6] is used to integrate differential equations.

For convenient modeling of a conic mill with liquid filler equipped with a hopper for collecting milling products, a computer program was developed in the Object Pascal language in the integrated programming environment Borland Delphi 7 (Fig. 1). The program allows, on the basis of computer experiments, to optimize the design parameters of the milling cutter [7]. 


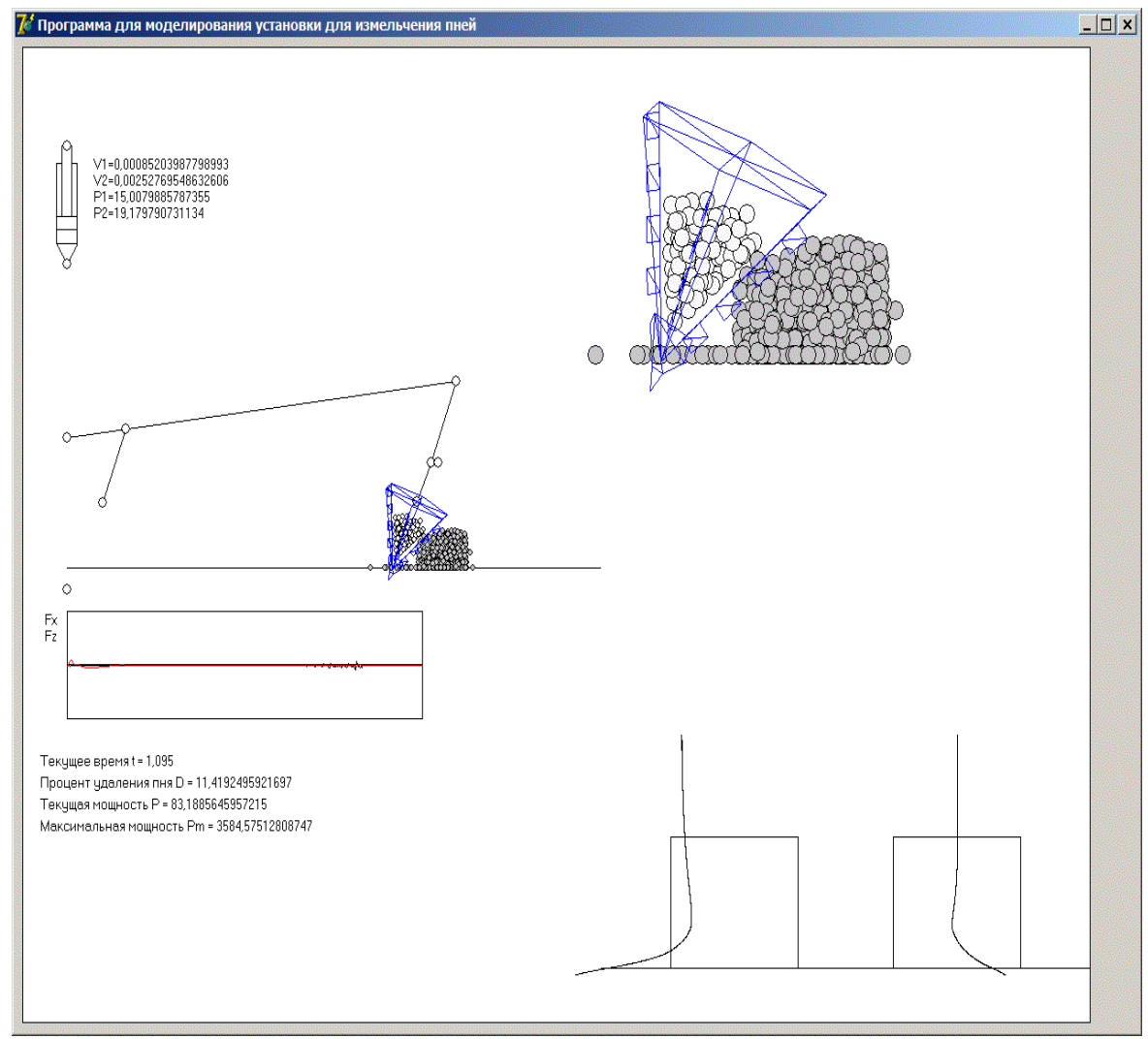

Fig. 1. Displaying the schematic image of the stump grinding cutter in the developed program.

During operation of the conical cutter it is difficult to position it precisely over the center of the stump. Therefore, a computer simulation was used to check the stability of the cutter motion in the array when the initial point of entry into the stump deviates within a wide range $[8,9]$.

\section{Results and discussion}

Figure 2 shows the trajectories of the centering element of the cutter depending on the position of the initial point $R_{\mathrm{B}}$ of the cutter entry into the stump in relation to the axis of the stump. In this series of computer experiments, RV was changed from $R_{\mathrm{B}}$ от $-0,75 \cdot R_{\Pi}$ до $0,75 \cdot R_{\Pi}$ in increments of $0.25-R_{\Pi}$ (fractions of the stump radius $R_{\Pi}$ are indicated).

As can be seen from Figure 2, regardless of the cutter entry point into the stump, the cutter moves in the stump almost vertically, i.e. measures taken to center the cutter ensure guaranteed movement of the cutter in the original direction, despite the asymmetric deflecting effect of the stump.

Only after reaching the base of the stump does the cutter begin to deviate from the vertical trajectory and gradually exit the stump in a lateral direction. The lateral movement of the cutter causes additional destruction of the stump. A series of trajectories for different cutter entry points into the stump is plotted in Figure 3 for easy analysis [10-13]. 

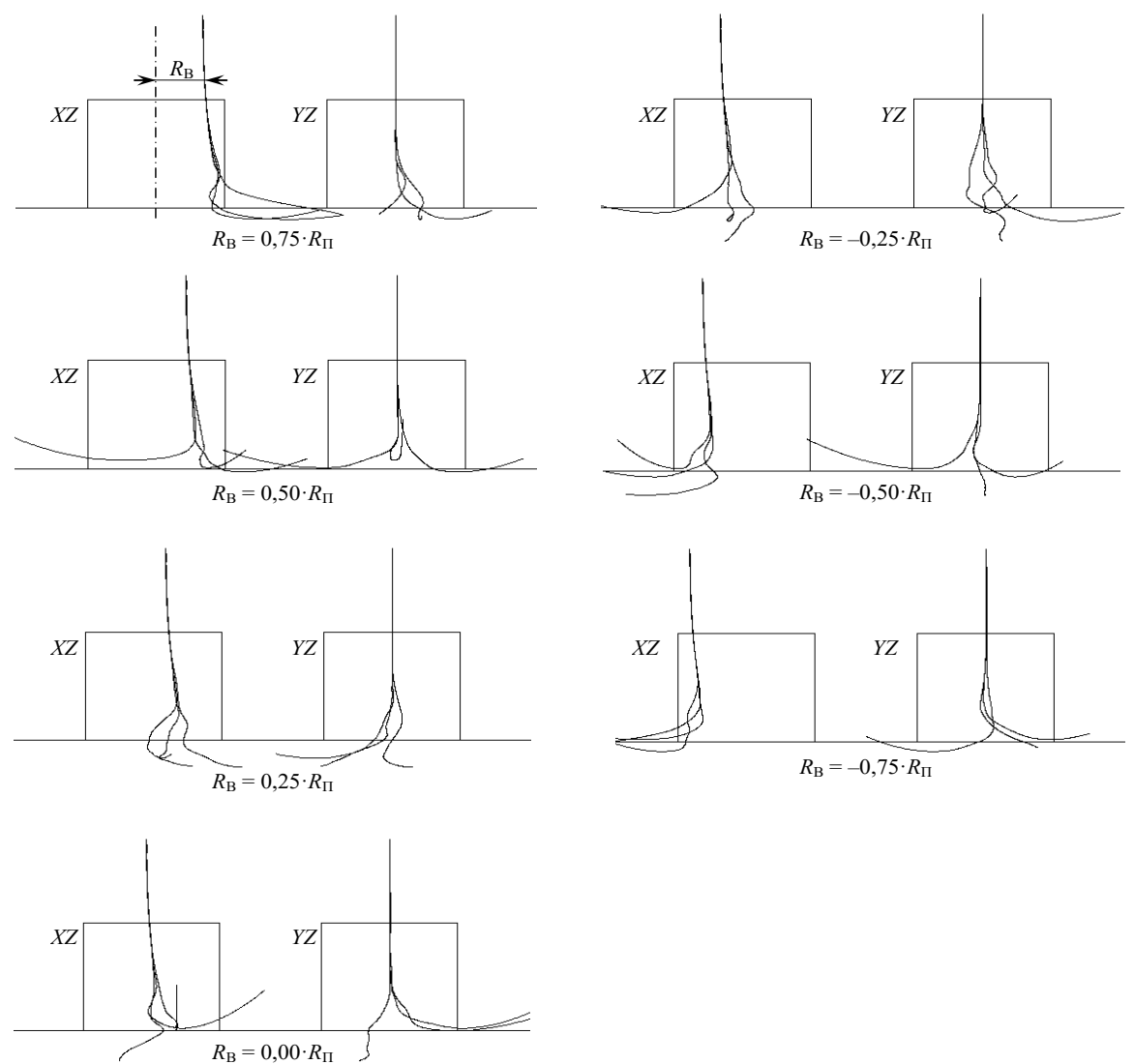

Fig. 2. Trajectories of the centering element of the cutter at different.

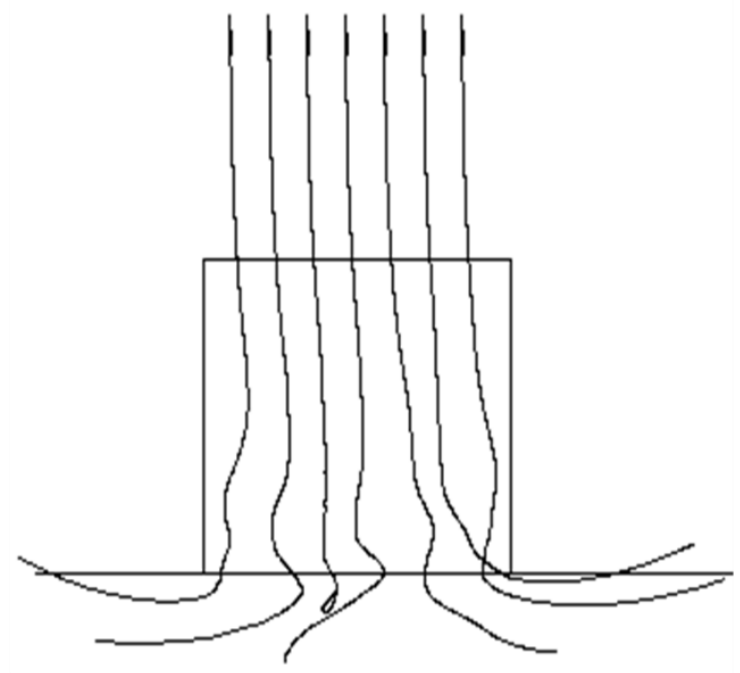

position $R_{\mathrm{B}}$ of the initial point of entry into the stump

Fig. 3. Characteristic trajectories of the cutter centering element motion at different positions of the initial entry point into the stump ( $X Z$ projection). 
As can be seen from Figure 3 , in a wide range of $R_{\mathrm{B}}$ (from $-0.75-R_{\Pi}$ to $0.75-R_{\Pi}$ ) the centering element of the cutter reaches the base of the stump almost vertically, and only then begins the exit of the cutter from the stump in the horizontal direction. Thus, the measures taken to center the cutter (liquid filler, feather guide knife) ensure that the cutter moves in the stump in the vertical direction, despite the asymmetric deflection of the stump.

Since the cutter moves in the stump on a complex random trajectory, the question arises as to how complete the stump removal will be. The completeness of stump removal is estimated in the model by the parameter $C_{\Pi}$, which is calculated by the formula $C_{\Pi}=(1-$ $\left.N_{\mathrm{CK}} / N_{\mathrm{CH}}\right) \cdot 100 \%$, where $N_{\mathrm{C}}$ and $N_{\mathrm{CH}}$ are the number of links between the stump elements at the beginning and at the end of the computer experiment (during modeling the cutter gradually separates the stump elements from each other, so the number of links between the elements is reduced).

As the cutter entry point into the stump is removed from the center of the stump (with increasing $R_{\mathrm{B}}$ ), the completeness of stump removal by $C_{\Pi}$ decreases (Figure 4 ). To obtain this dependence, a series of computer experiments was conducted in which the $R_{\mathrm{B}} / R_{\Pi}$ values were varied from 0 to $90 \%$ in steps of $10 \%$.

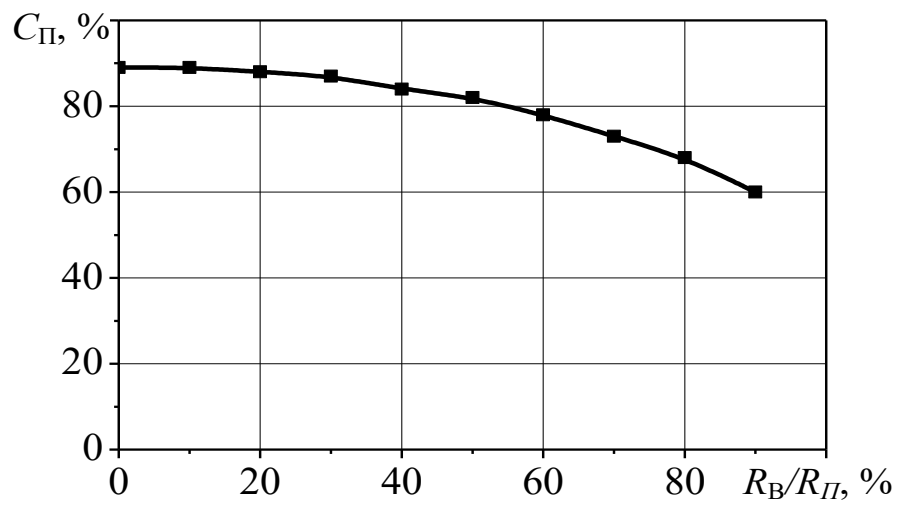

Fig. 4. Dependence of stump removal completeness on the position of the initial entry point into the stump.

The decreasing character of the $C_{\Pi}\left(R_{\mathrm{B}} / R_{\Pi}\right)$ curve can be explained by the fact that as the initial cutter entry point moves away from the stump center, first, the cutter chops the stump asymmetrically, leaving untouched wood from the side opposite to the entry point, and second, the cutter leaves the stump faster in the lateral direction, leaving untouched wood at the bottom of the stump. It should be noted that in a wide range of $R_{\mathrm{B}} / R_{\Pi}$ (from 0 to $55 \%$ ) the stump is well chopped (more than $80 \%$ ), and only at $R_{\mathrm{B}} / R_{\Pi}$ over $55 \%$ the completeness of stump removal gradually decreases to $60 \%$. Thus, the advantage of the developed device is that it does not require a very precise initial positioning of the cutter.

\section{Conclusion}

Computer experiments allow us to state that the measures taken to center the cutter (liquid filler, feather guide) allow not only to sustain the vertical movement of the cutter in the stump, but also to return the cutter to the stump center during significant deviations caused by random fluctuations in the mechanical properties of the stump. 


\section{References}

1. M.A. Platonova, M.V. Drapalyuk, A.A. Platonov, Journal of Forest Engineering, 5, 4 (2015)

2. S.S. Morkovina, M.V. Drapalyuk, E.V. Baranova, Journal of "Forest Engineering Journal", 5, 3 (2015)

3. D.Y. Druchinin, E.V. Pozdnyakov, Journal of coniferous boreal zone, 37, 6 (2019)

4. V. Y. Zorin, Journal of "Pulp, Paper, Cardboard", 8 (1976)

5. B.V. Karamantsev, Journal "Technics in agriculture", 4 (1972)

6. S. V. Fokin, O.N. Shportko, Journal "Actual directions of scientific research of the XXI century", 3, 2 (2015)

7. S. Fokin, et al, IOP Conf. Ser.: Earth Environ. Sci.(2021)

8. O.O. Kovalev, Conference "Advanced Problems in Mechanics" (St. Petersburg, 2013)

9. A.Yu. Suravkin, Journal of Science and Education, 7 (2012)

10. S.V. Bereznikov, S.V. Fokin, Journal of Fundamental Research, 10 (2013)

11. V. V. Sergeev, S. Yu. Korostelev, S. G. Psakhie, Journal of the Proceedings of Tomsk Polytechnic University, 312, 5 (2008)

12. A.V. Gerasimov, R.O. Cherepanov, Journal "Izvestiya vuzov. Physics", 7/2 (2009)

13. M.V. Drapalyuk, V.S. Polev, Proceedings of Higher Educational Institutions. Forestry Journal, 6 (2010)

14. A.P. Potapov, I.B. Petrov, Journal "Bulletin of the I. Kant Russian State University", $10(2009)$

15. M.N. Davydov, V.K. Kedrinsky, Journal of Applied Mechanics and Theoretical Physics, 54, 6 (2013)

16. A.A. Lukyanov, V.B. Penkov, Journal "Vestnik of Samara University, Natural Science Series", 56, 6 (2007)

I. R. Shegelman, S.B. Vasiliev, A. Lapatin, Mobile choppers: justification of parameters and technological calculations (Petrozavodsk, PetrSU Publishing House, 1998) 